\title{
Isolation and Characterization of Multifunctional Yeast as Plant Probiotics for Better Crop Nutrition in Pulses
}

\author{
B. Jeberlin Prabina ${ }^{1 *}$, K. Kumutha ${ }^{2}$, R. Anandham ${ }^{3}$ and P. Durga ${ }^{2}$ \\ ${ }^{I}$ Department of SS\&AC, AC\&RI., Killikulam, India \\ ${ }^{2}$ Department of Agriculture Microbiology, AC\&RI., Madurai, India \\ ${ }^{3}$ Department of Agriculture Microbiology, TNAU, Coimbatore, India \\ *Corresponding author
}

\section{A B S T R A C T}

Pulses being important source of protein and micronutrients find its place in national food

Keywords

Isolation,

Characterization,

Multifunctional,

Yeast, Plant

Article Info

Accepted:

17 December 2018

Available Online:

10 January 2019 security. Plant probiotic microbes play an important role in producing safe and nutritious pulses. In this work we characterized plant probiotic yeast from different sources and investigated its multifunctional activity in promoting the growth of black gram. Of the twenty isolates, two isolates one from the seeds of pomegranate (POY5) and the other one from grapes (GRY4) were selected for the study. Alignment results of the 18S rDNA sequences using ITS1 and ITS4 revealed POY5 as Pichia kudriavzevii and GRY4 as Issatchenkia terricola. Interestingly, both the isolates were positive for the plant growth promoting characteristics such as phosphorus solubilization, zinc solubilization, auxin, siderophore, ACC deaminase and hydrogen cyanide production that signify them as plant probiotics. Seed imbibition with the probiotic yeast recorded an increase in germination per cent of 9 and $8.8 \%$ by POY5 and GRY4 respectively over control. Significant difference in root and shoot length of black gram seedlings treated with probiotic yeast were recorded. It is concluded that these multi-functional yeast could be exploited as bioformulation for better crop nutritional security in black gram.

\section{Introduction}

It is interesting to note that the rhizosphere of plants is home to diversified group of microbes many of which interact with each other and with the plants either way. With the exploration of the beneficial role of these microbes, called as plant growth promoting microbes, significant interest has been created among the researchers for the exploitation of these microbes for better and sustainable agriculture. The benefits enjoyed by the plants up on inoculation with these beneficial microbes include improved availability of nutrients, reduced infection by pathogens and enhanced resistance to abiotic stress such as drought, temperature and salinity (Riggs, et al., 2001; Martinez Viverol et al., 2010; Kim et al., 2011 ).

The common effects that could be realised in plants due to the beneficial microbes are 
improvement in germination, seedling vigor, biomass production, root hair development, photosynthetic efficiency, improved plant biochemical composition flowering, and yield. Among the growth promoting microbes, beneficial bacteria commonly referred as Plant Growth Promoting Bacteria (PGPR) (Vessey, 2003) are widely exploited and has got much attention.

Plant Growth Promoting Fungi (PGPF) is also gaining importance and is reported to improve the plant quality (Zhou et al., 2018) that fungi and yeast stand in line for exploration with much potential for improving the food quality. Yeasts are unicellular fungi that are distributed more in rhizosphere region than the nonrhizosphere region (Botha, 2011).

A diverse range of yeasts exhibit plant growth promoting characteristics, including control of pathogens (El-Tarabily, 2004; El-Tarabily and Sivasithamparam, 2006; Sansone et al., 2005); Plant growth hormone production (Nassar et al., 2005); Phosphorus solubilisation (Falih and Wainwright, 1995; Mirabal Alonso et al., 2008); Nitrogen and sulphur oxidation (Falih and Wainwright, 1995); and siderophore production (Sansone et al., 2005). Here, our aim of investigation was to identify potential multifunctional plant growth promoting yeast from different sources that would help in sustaining the black gram nutrition for better tomorrow.

\section{Materials and Methods}

A total of twenty different yeast were isolated from grapes, pomegranate, tomato and black gram samples using the Yeast Extract Peptone Dextrose (YEPD) agar medium supplemented with $250 \mu \mathrm{g} / \mathrm{ml}$ chloramphenicol with $\mathrm{pH}$ 6.56.7 (Nassar et al., 2005). Among the twenty, molecular characterization was done for the two selected efficient yeast isolates by ITS 1/ ITS 4 sequencing.
Molecular characterization of the yeast isolates

The genomic DNA from the selected isolates namely GRY4 and POY5 was isolated using the standard protocol using HiPurA ${ }^{\mathrm{TM}}$ Yeast Genomic DNA Purification Kit.

Genomic DNA of the yeast isolates were amplified using ITS1 (5'-TCCGTAGGTG AACCTGCGG -3') and ITS4 (5'-TCCTCCGCT TATTGATATGC -3'). The amplified product was sequenced using fluorescent dye terminator method (ABI prism equipment and a Bigdye $^{\mathrm{TM}}$ Terminator cycle sequencing ready reaction kit V.3.1). Sequencing was performed in Macrogen, South Korea. Sequences were aligned and identified the closest neighbor using NCBI Basic Local Alignment Search Tool (BLAST).

Plant growth promoting characteristics of yeast isolates

\section{Phosphorus solubilization by the yeast isolates}

The phosphorus solubilization ability of the yeast isolates was quantitatively determined by inoculation in NBRI-BPB medium, 2001supplemented with $0.5 \%$ insoluble phosphorus as tri-calcium phosphate and incubated at $30 \pm 1^{\circ} \mathrm{C}$ for 3 days.

The $\mathrm{pH}$ of the medium was adjusted to 7.0 before sterilization in autoclave. Flasks were inoculated with metabolically active yeast culture@1\% having a population of $8 \times 10^{5}$ cells. The cultures were maintained under aerobic condition with shaking $(100 \mathrm{rpm})$ for 3 days at $30{ }^{\circ} \mathrm{C}$. The samples were centrifuged at $5000 \times \mathrm{g}$ for $15 \mathrm{~min}$ and the $\mathrm{pH}$ and soluble $\mathrm{P}$ in the supernatant were analysed. The $\mathrm{pH}$ was measured with a PHM210 meter. Soluble phosphorus was measured using the ascorbic acid method (Olsen et al., 1954). 
Indole acetic acid production by the yeast isolates

IAA production was estimated using the modified method of Gordon and Weber, 1951. The isolates were grown overnight in YEPD broth and transferred to fresh broth supplemented with $1 \%$ tryptophan incubated for $48 \mathrm{~h}$ at $30 \pm 1^{\circ} \mathrm{C}$ in a rotary shaker. Then, the cultures were centrifuged at $15,000 \mathrm{rpm}$ for 10 min. One millilitre of the supernatant was mixed with $2 \mathrm{~mL}$ of $\mathrm{Fe}-\mathrm{H}_{2} \mathrm{SO}_{4}$ solution $(1 \mathrm{~mL}$ of $0.5 \mathrm{M} \mathrm{FeCl}_{3} \cdot 6 \mathrm{H}_{2} \mathrm{O}$ in $75 \mathrm{~mL}$ of $6.13 \mathrm{M}$ $\mathrm{H}_{2} \mathrm{SO}_{4}$ ) and incubated in the dark for $45 \mathrm{~min}$. under dark condition. The reddish pink colour developed was read at an absorbance of 530 nm (UV-160 A spectrophotometer, Shimadzu, Japan) and the amount of IAA produced was calculated from the standard graph obtained with 0.5 to $10 \mu \mathrm{g} \mathrm{ml}^{-1}$ of IAA.

Zinc solubilization ability of the yeast isolates

Zinc solubilization assay was carried out in culture medium supplemented with $0.1 \%$ insoluble zinc compound as $\mathrm{ZnO}$ (Bunt and Rovira, 1955). Flasks were inoculated with metabolically active yeast culture @ 1\% having a population of $8 \times 10^{5}$ cells. The cultures were maintained under aerobic condition with shaking (100 rpm) for 5 days at $30^{\circ} \mathrm{C}$. The samples were centrifuged at $5000 \times \mathrm{g}$ for $15 \mathrm{~min}$ and the $\mathrm{pH}$ and soluble zinc in the supernatant were analysed through Inductively Coupled Plasma Optical Emission Spectroscopy (ICP-OES) Teledyne Leeman Labs, Prodigy Spec., USA.

Siderophore production by the yeast isolates

The modified Chrome azurol S (CAS) assay (Milagres et al., 1999) was used to test the ability of yeast isolates to produce iron binding compound siderophores in solid medium. CAS blue agar and YEPD agar plates were prepared. Half of the YEPD medium was cut and replaced by CAS blue agar. The yeast isolates were spot inoculated on to YEPD agar half near the border line and plates were incubated in the dark at $30 \pm 1^{\circ} \mathrm{C}$ for 10 days. Un-inoculated CAS agar plate served as control. The CAS reaction was determined by measuring the position or distance of the advancing colour change (in $\mathrm{mm}$ ) in the CAS blue agar starting from the border line between the two halves during incubation period of 10 days (Schwyn and Neilands, 1987).

\section{Hydrogen cyanide (HCN) production by the yeast isolates}

The yeast isolates were streaked onto King's $B$ medium amended with glycine. Whatman No.1 filter paper soaked in picric acid $(0.05 \%$ solution in $2 \%$ sodium carbonate) was placed inside the lid of each Petriplate. The plates were then sealed air-tight with parafilm and incubated at $30 \pm 1^{\circ} \mathrm{C}$ for $48 \mathrm{~h}$. A change in colour of the filter paper from deep yellow to reddish-brown indicates the production of Hydrogen cyanide (Bakker and Schipperes, 1987).

\section{ACC deaminase activity of the yeast isolates}

The presence of ACC deaminase activity was determined as described by Dell'Amico et al., (2005). About $24 \mathrm{~h}$ old yeast isolates grown in nitrogen free DF medium with ACC as carbon source. After inoculation, the cultures were grown at $28^{\circ} \mathrm{C}$ with continuous shaking and optical density at $600 \mathrm{~nm}$ was read for 8 days.

Growth indicates the potential for the microorganism to use ACC as nitrogen source through deamination.

\section{Results and Discussion}

A total of 20 yeast isolates were obtained from tomato, grapes, pomegranate and black gram. 
All the isolates were tested for the plant growth promoting traits such as production of IAA, siderophore, hydrogen cyanide, zinc solubilization and phosphate solubilization.

Based on the results two isolates viz., GRY4 and POY5 that were positive for recognized plant growth promoting traits were selected for further plant growth promotion of black gram under in vitro conditions. The results are presented in Table 1.
Molecular identification of the efficient isolates of yeast

Genomic DNA of the yeast isolates were amplified using ITS1 and ITS4. Based on partial 18SrRNA sequencing, these yeast isolates were identified. The isolates were submitted in Genbank (NCBI) and accession numbers were obtained. The amplified sequence of GRY4 showed 98\% similarity to Issatchenkiaterricola (363 bp) and POY5 showed 93\% similarity to Pichiakudriavzevii (506 bp).

\begin{tabular}{|l|l|l|l|l|l|}
\hline $\begin{array}{l}\text { S. } \\
\text { No. }\end{array}$ & Yeast isolates & Closest Neighbour & $\begin{array}{l}\text { Length of the } \\
\text { sequence (bp) }\end{array}$ & $\begin{array}{l}\text { \% } \\
\text { Similarity }\end{array}$ & $\begin{array}{l}\text { NCBI } \\
\text { accession No. }\end{array}$ \\
\hline 1. & GRY4 & Issatchenkiaterricola & 363 & 98 & MG547741 \\
\hline 2. & POY5 & Pichiakudriavzevii & 506 & 93 & MG547742 \\
\hline
\end{tabular}

Studies on plant growth promoting characteristics of the yeast isolates

The ability to solubilize tri-calcium phosphate by the yeast isolates was more on $3^{\text {rd }}$ day of incubation with a recorded value of 386 and $311 \mu \mathrm{g} \mathrm{ml}^{-1}$ by Issatchenkia terricola and Pichia kudriavzevii respectively. The earlier report by Narsian et al., (2010) documented solubilization of $697 \mu \mathrm{g} \mathrm{ml}^{-1}$ of phosphorus at 11 days of incubation by Pichia subpelliculosa.

Among the two test isolates, Pichia kudriavzevii produced higher IAA of about $21.62 \mu \mathrm{g} \mathrm{ml}^{-1}$ and $18.81 \mu \mathrm{g} \mathrm{ml} \mathrm{m}^{-1}$ by Issatchenkia terricola. Amprayn et al., 2012 reported a quantity of $2.6 \mu \mathrm{g} \mathrm{ml}{ }^{-1}$ IAA production by Candida tropicalis whereas Sun et al., 2014 recorded IAA production of $147.4 \pm 2.7 \mu \mathrm{g} \mathrm{ml}^{-1}$ in A. pullulans with exogenous tryptophan. The variation in the quantity is due to the inherent capacity to synthesise IAA by different genera of yeast.

The quantity of solubilization of zinc by the yeast isolates was studied under in-vitro condition with zinc oxide that recorded a quantity of $174 \pm 1.23 \mu \mathrm{g} \mathrm{ml}^{-1}$ to $181 \pm 1.76 \mu \mathrm{g}$ $\mathrm{ml}^{-1}$. Earlier work by Panneerselvam et al., (2013) estimated a solubilization quantity of $232.4 \pm 8.46 \mu \mathrm{g} \mathrm{ml}^{-1}$ with Pseudomonas putida. Variation between the isolates to solubilize the same or different source of insoluble zinc compounds has been noticed by earlier workers also (Di simine et al., 1998; Fasim et al., 2002; Saravanan et al., 2003; Shahab and Ahmed, 2008).

Solubilization of zinc by the yeast isolates was attributed to the production of organic acid that has been realised with the shift in $\mathrm{pH}$ of the medium from 7.0 to 3.5.

Among the desirable characteristics of a biocontrol agent, ability for siderophore production is important as it could sequester the iron, making it unavailable for pathogens. Vero et al., (2013) evaluated the production of siderophore in yeasts from Antartic soil and Spadaro et al., (2011) attributed siderophore production by the yeast isolate Metschnikowia pulcherrima MACH1 for its bio-control capacity. 
Siderophores, such as pyoverdine and pyochelin, are biologically active derivatives of small peptides or peptide-like molecules (Byers and Arceneaux, 1998). Viable cells of S. cerevisiae possess heme molecules that are connected with inducible ferri-reductase activity and iron uptake (Lesuisse and Labbe, 1989). Though the siderophore production and uptake had been demonstrated in the yeast Saccharomyces cerevisiae, the mechanism was due to the ferric ion reduction system, by Fre1p and Fre $2 p$ proteins at the cell surface, followed by the uptake of iron via the high and low-affinity iron uptake systems (Heymann et al., 2002). In the present study, not all the twenty isolates were positive for siderophore production. But the selected two isolates were able to release siderophore, making the yeast isolates a multifunctional plant growth promoter.

Table.1 Plant growth promoting traits of the yeast isolates. Values are means of three replicates \pm standard errors (SE)

\begin{tabular}{|c|c|c|}
\hline PGP traits studied & $\begin{array}{c}\text { Issatchenkiaterricola } \\
\text { (GRY4) }\end{array}$ & $\begin{array}{l}\text { Pichiakudriavzevii } \\
\text { (POY5) }\end{array}$ \\
\hline $\begin{array}{l}\text { Phosphorus solubilization } \\
{\left[\text { Total P release }\left(\mu \mathrm{g} \mathrm{ml}^{-1}\right)\right]}\end{array}$ & $386 \pm 14$ & $311 \pm 10$ \\
\hline IAA production $\left[\mu \mathrm{g} \mathrm{ml}^{-1}\right]$ & $18.81 \pm 0.04$ & $21.62 \pm 0.06$ \\
\hline $\begin{array}{l}\text { Zinc solubilization }[\mathrm{Zn} \\
\left.\text { release }\left(\mu \mathrm{g} \mathrm{ml}^{-1}\right)\right]\end{array}$ & $174 \pm 1.23$ & $181 \pm 1.76$ \\
\hline $\begin{array}{l}\text { Siderophore production } \\
\text { [nmol } \quad \alpha \text {-Ketobutyrate } \\
\text { released } \min \mathrm{mg}^{-1} \text { of } \\
\text { protein] }\end{array}$ & $2.4 \pm 0.002$ & $2.69 \pm 0.014$ \\
\hline $\begin{array}{l}\text { Hydrogen } \\
\text { production }\end{array}$ & Positive & Positive \\
\hline ACC deaminase & Positive & Positive \\
\hline
\end{tabular}

Plant growth promoting rhizobacteria produce chemical compounds with different benefits for the plant. Among them hydrogen cyanide is recognized as a biocontrol agent, based on its toxicity against plant pathogens and ability to form complexes with transitional metals in the mineral substrate, (Rijavec and Lapanje, 2016), in which HCN is involved in increasing the availability of phosphates by metal chelation. Wongfun et al., (2014) recorded the role of hydrogen cyanide in mobilization of elements from rock phosphate minerals. Both the two test isolates, Pichia kudriavzevii and Issatchenkia terricola were positive for hydrogen cyanide production that the ability to produce $\mathrm{HCN}$ could be considered as a growth promoting trait. The function of ACC deaminase in plant-microbe systems has been well studied and resulted in decreased ethylene production and subsequent stimulation of plant root elongation (Glick et al., 2007; Yim et al., 2010).

Amprayn et al., (2012) the ability of the soil yeast Candida tropicalis HY, to utilize aminocyclopropane-1-carboxylate (ACC) as sole source of nitrogen, indicative of high ACC deaminase activity.

The studies with Pichia kudriavzevii and Issatchenkia terricola indicated the ability 
of the yeast isolates to utilize ACC as carbon source, proving the ability to have ACC deaminase activity.

\section{Seedling assay in black gram under in vitro condition}

For seed imbibition study along with the best isolates POY4 was also included to compare the performance among the yeast isolates. Seed imbibition with yeast isolates influenced the germination of seeds significantly. Seed imbibition with the isolate POY5 recorded the higher germination of $77 \%$ compared to the uninoculated control $(68 \%)$ that accounted for an increase in germination per cent of 9 and $8.8 \%$ by POY5 and GRY4 respectively over control. Root length was significantly influenced by imbibition treatments. Higher root length was observed in GRY4. In case of shoot length, though inoculation exhibited significant influence, all the isolates were on par. In turn, significant influence on vigour index was observed due to seed imbibition with yeast isolates and the maximum was observed with POY5 isolate (3619) against control (2257) seedlings. Seeds imbibed with the yeast isolate POY4 had not significantly influenced the seedling compared to un-inoculated control. The overall results revealed the positive influence of yeast isolates on seedling vigour of black gram.

In conclusion, the plant based yeasts IssatchenkiaterricolaGRY4 and Pichia kudriavzevii POY 5 are multi-functional that they could solubilize phosphorus, zinc nutrients solubilization; produce auxin, siderophore, ACC deaminase and hydrogen cyanide that either directly or indirectly affect the plants. Significant influence on vigor index of black gram on seed imbibition with the yeast isolates strongly substantiates the growth promoting nature of the yeast isolates.
The work and the results that were obtained authenticates the prospects of yeast to be developed as formulation for black gram to ensure crop nutritional security.

\section{References}

Botha, A., 2011. The importance and ecology of yeasts in soil. Soil Biol. Biochem., 43, 1-8.

Bunt and Rovira, 1955. Studies of some sub Antarctic soils. J. Soil Sci., 6:119-128

Byers, B. R. and J. E. L. Arceneaux, 1998 In: Iron Transport and Storage in Microorganisms, Plants, and Animals (Sigel, A., and Sigel, H., eds) 35: 3766, Marcel Dekker, New York

Dell'Amico, E., L. Cavalca and V. Andreoni. 2005. Analysis of rhizobacterial communities in perennial Graminaceae from polluted water meadow soil and screening of metal-resistant, potentially plant growth-promoting bacteria. FEMS Microbiol. Ecol., 52:153-162.

Di Simine, C. D., J. A. Sayer and G. M. Gadd. 1998. Solubilization of zinc phosphate by a strain of Pseudomonas fluorescens isolated from forest soil. Biol. Fertile. soils, 28: 87-94.

El-Tarabily, K.A., 2004. Suppression of Rhizoctoniasolani diseases of sugar beet by antagonistic and plant growthpromoting yeasts. J. Appl. Microbiol. 96: 69-75.

El-Tarabily, K.A and K. Sivasithamparam. 2006. Potential of yeasts as bio-control agents of soil-borne fungal plant pathogens and as plant growth promoters. Mycoscience. 47: 25-35

Falih, A.M., Wainwright, M., 1995. Nitrification, S-oxidation and Psolubilization by the soil yeast Williopsis californica and by Saccharomyces cerevisiae. Mycol. Res. 99, 200-204.

Fasim, F., N. Ahmed, R, Pasons and G.M. 
Gadd. 2002. Solubilization of zinc salts by a bacterium isolated from the air environment of a tannery. FEMS Microbiol. Lett., 213: 1-6

Glick, B.R., Z. Cheng, J. Czarny and J. Duan. 2007. Promotion of plant growth by ACC deaminase-producing soil bacteria. European Journal of Plant Pathology, 119: 329-339.

Gordon, S.A and R. P Weber. 1951. Colorimetric estimation of indole acetic acid. Plant Physiol. 26: 192-195

Heymann, P., M. Gerads, M. Schaller, F. Dromer, G. Winkelmann and J.F. Ernst. 2002. The siderophore iron transporter of Candida albicans (Sit1p/Arn1p) mediates uptake of ferrichrome-type siderophores and is required for epithelial invasion. Infection and Immunity, 70: 52465255

Kim, Y, C.J. Leveau, B.B, McSpadden Gardener, E.A. Pierson, L.S. Pierson and C.M. Ryu III. 2011. The multifactorial basis for plant health promotion by plant associated bacteria. Appl. Environ. Microbiol., 77: 1548-1555.

Lesuisse, E and P. Labbe. 1989. Reductive and non-reductive mechanisms of iron assimilation by the yeast Saccharomyces cerevisiae. J. Gen. Microbiol., 135: 257-263.

Martinez-Viverol, O., M.A. Jorquera, D.E. Crowley, G. Gajardo and M.L. Mora. 2010. Mechanisms and practical considerations involved in plant growth promotion by rhizobacteria. J. Soil. Sci. Plant Nutr., 10: 293-319.

Milagres, A.M.F., A. Machuca and D. Nepoleao. 1999. Detection of siderophore production from several fungi and bacteria by a modification of chrome Azurol S (CAS) agar plate assay. Journal of Microbiological methods. 37(1):1-6
Mirabal Alonso, L., D. Kleiner, and E. Ortega. 2008. Spores of the mycorrhizal fungus Glomus mosseae host yeasts that solubilize phosphate and accumulate polyphosphates. Mycorrhiza 18: 197-204.

Narsian, V., A.A.S.M Samaha and H.H. Patel. 2010. Rock phosphate dissolution by specific yeast. Indian Journal of Microbiology, 50: 57-62.

Nassar, A.H., K.A. El-Tarabily and K. Sivasithamparam. 2005. Promotion of plant growth by an auxin-producing isolate of the yeast Williopsissaturnus endophytic in maize (Zeamays L.) roots. Biology and Fertility of Soils, 42: 97-108.

Olsen, S.R., C.V. Cole, F.S. Watanabe and L.A. Dean. 1954. Estimation of available phosphorus in soils by extraction with sodium bicarbonate. U.S. Dep. of Agric. Circ.,939

Panneerselvam, P.,B. Sarith, S. Mohanda, K.K. Upret, S. Poovarasa, V.V. Sulladmat and R. Venugopalan. 2013. Biological Agriculture and Horticulture, 29(2): 118- 131.

Riggs, P. J., M. K. Chelius, L. Iniquez, S.M. Kaeppler and E. W. Triplett. 2001. Enhanced maize productivity by inoculation with diazotrophic bacteria. Aust. J. Plant Physiol., 28: 829-836.

Rijavec, T., and A. Lapanje. 2016. Hydrogen cyanide in the rhizosphere: not suppressing plant pathogens, but rather regulating availability of phosphate. Frontiers in Microbiology, $7 \mathrm{Pp}$.

Sansone, G.,I. Rezza, V. Calvente, D. Benuzzi and M.I.S.D. Tosetti. 2005. Control of Botrytis cinerea strains resistant to iprodione in apple with rhodotorulic acid and yeasts. Postharvest Biol. Tech. 35: 245-251.

Saravanan, V., S. Subramoniam and S. Anthoni Raj. 2003. Assessing in-vitro 
solubilisation potential of different zinc solubilizing bacterial isolates. Brazilian. J. Microbiol., 34: 121- 125.

Schwyn, B and J.B. Neilands. 1987. Universal Chemical Assay for the Detection and Determination of Siderophores. Analytical Biochemistry, 160: 47-56

Shahab, S and N. Ahmed, N. 2008. Effect of various parameters on the efficiency of zinc phosphate solubilisation by indigenous bacterial isolates. African J. Biol., 7: 1543- 1549.

Spadaro, D., D. Zhang, A. Garibaldi and M. Gullino. 2011. The Role of Competition for Iron and Cell Wall Degrading Enzymes in Mechanism of Action of Postharvest Bio-control Agents. ActaHorticulturae (ISHS). 905: 87-102.

Stewart, W.D., G.P. Fitzgerald and R.H. Burris. 1967. In situ studies on $\mathrm{N}_{2}$ fixation using the acetylene reduction technique. Proc. Natl. Acad. Sci. U S A. 58(5): 2 071-2078.

Sun, P.F., W.T. Fang, L.Y. Shin, J.Y. Wei and S.F. Fu. 2014. Indole-3-Acetic Acid- Producing Yeasts in the Phyllosphere of the Carnivorous Plant Droseraindica L. PLoS ONE, 9:114196.

Vero, S., G. Garmendia,B.Gonzalez, O.

\section{How to cite this article:}

Jeberlin Prabina, B., K. Kumutha, R. Anandham and Durga, P. 2019. Isolation and Characterization of Multifunctional Yeast as Plant Probiotics for Better Crop Nutrition in Pulses. Int.J.Curr.Microbiol.App.Sci. 8(01): 2711-2718. doi: https://doi.org/10.20546/ijcmas.2019.801.286
Bentancur and M. Wisniewski. 2013. Evaluation of yeasts obtained from Antarctic soil samples as bio-control agents for the management of postharvest diseases of apple (Malus domestica). FEMS Yeast Research, 13: $189-190$.

Vessey, J.K., 2003. Plant growth promoting rhizobacteria as bio-fertilizers. Plant Soil. 255: 571-586.

Wongfun, N., M. Plötze, G. Furrer and H. Brandl. 2014. Weathering of granite from the Damma glacier area: the contribution of cyanogenic bacteria. Geomicrobiology Journal, 31: 93-100

Yim, W.J., P.S. Chauhan, M. Madhaiyan, S.C. Tipayno, T.M.Sa. 2010. Plant growth promontory attributes by 1 aminocyclopropane-1-carboxylate

(ACC) deaminase producing Methylobacterium oryzae strains isolated from rice. In: $19^{\text {th }}$ World Congress of Soil Science, Soil Solutions for a hanging World, Brisbrane, Australia, pp. 96-99.

Zhou, L.S., K. Tang and S.X. Guo. 2018. The Plant Growth Promoting Fungus (PGPF) Alternaria sp. A13 markedly enhances Salvia miltiorrhiza root growth and active ingredient accumulation under greenhouse and field conditions. Int. J. Mol Sci., 16:19 